\title{
A novel implantation technique for engineered osteo-chondral grafts
}

\author{
C. Candrian $\cdot$ Andrea Barbero $\cdot$ E. Bonacina $\cdot$ S. Francioli $\cdot$ \\ M. T. Hirschmann - S. Milz • V. Valderrabano - M. Heberer · \\ I. Martin · M. Jakob
}

Received: 12 November 2008/ Accepted: 18 February 2009/Published online: 21 March 2009

(C) Springer-Verlag 2009

\begin{abstract}
We present a novel method to support precise insertion of engineered osteochondral grafts by pulling from the bone layer, thereby minimizing iatrogenic damage associated with direct manipulation of the cartilage layer. Grafts were generated by culturing human expanded chondrocytes on Hyaff ${ }^{\circledR}-11$ meshes, sutured to Tutobone $^{\circledR}$ spongiosa cylinders. Through the bone layer, shaped to imitate the surface-contours of the talar dome, two sutures were applied: the first for anterograde implantation, to pull the graft into the defect, and the second for retrograde correction, in case of a too deep insertion. All grafts could be correctly positioned into osteochondral lesions created in cadaveric ankle joints with good fit to the surrounding cartilage. Implants withstood short-term dynamic stability tests applied to the ankle joint, without delamination or macroscopic damage. The developed technique, by allowing precise and stable positioning of osteochondral grafts without
\end{abstract}

C. Candrian - A. Barbero - S. Francioli · V. Valderrabano · M. Heberer · I. Martin $(\bowtie) \cdot$ M. Jakob

Departments of Surgery and Biomedicine, Institute for Surgical Research \& Hospital Management, University Hospital Basel, Hebelstrasse 20, ZLF, Room 405, 4031 Basel, Switzerland e-mail: imartin@uhbs.ch

A. Barbero

e-mail: abarbero@uhbs.ch

C. Candrian - M. T. Hirschmann

Department of Orthopaedic Surgery and Traumatology,

Kantonsspital, Bruderholz, Switzerland

E. Bonacina

I.R.C.C.S Istituto Ortopedico Galeazzi, Milan, Italy

S. Milz

AO Research Institute, Davos, Switzerland iatrogenic cartilage damage, is essential for the implantation of engineered tissues, where the cartilage layer is not fully mechanically developed, and could be considered also for conventional autologous osteochondral transplantation.

Keywords Tissue engineering - Osteochondral lesion · Ankle joint · Osteochondral transplantation

\section{Introduction}

Osteochondral lesions (OCL) of the ankle joint (i.e., defects which affect both the articular cartilage and the underlying subchondral bone) are typically caused by traumatic injuries, chronic ankle instability, malalignment or avascular necrosis $[18,19]$. In order to prevent the onset of premature osteoarthritic changes of the ankle joint $[2,3,16,20]$, the treatment of symptomatic OCL of the talus has been approached using a variety of surgical options, such as microfracturing, autologous chondrocytes transplantation [6] or autologous osteochondral transplantation [8]. Despite the encouraging reported clinical results in the clinical routine use of autologous osteochondral grafts $[8,22]$, the technique (often referred to as 'mosaicplasty') still suffers from several problems such as the limited availability of grafts, the frequent donor site morbidity in up to $70 \%$ of patients $[7,22]$, and the difficulty to match the size and shape of the graft with the defect. Moreover, it was reported that the commercially available extraction and implantation instruments, based on press-fit techniques and pushing of the graft with a probe into the defect zone, can lead to cell death in the cartilage layer of the native autologous osteochondral graft $[9,15]$. 
Some of the main limitations of the mosaicplasty technique could be solved by the use of engineered osteochondral grafts, whereby the patient's own cells, combined with three dimensional (3D) porous materials of predefined size and shape, would generate a superficial cartilaginous layer and an underlying calcified tissue [17]. However, in addition to the biological and engineering challenges associated to the production of such grafts [12], also the implantation techniques will need to be revised. In fact, engineered composite implants would be more prone to iatrogenic damage than native osteochondral tissues during implantation, due to their relatively inferior mechanical properties, and therefore their insertion, orientation and fixation would result more critical.

Only few studies have so far addressed the issue of improving the implantation technique for engineered chondral or osteochondral grafts. In particular, Kandel et al. [10] advocated the use of a stainless steel pin $(1 \mathrm{~mm})$, inserted directly through the cartilage layer of the implanted osteochondral graft. This resulted in a small defect in the middle of the cartilaginous layer, which was still microscopically visible 9 months after implantation in a sheep model.

We aimed the study at developing a new, simple surgical technique for the implantation of tissue engineered composite grafts in a standard osteochondral defect of the talus, addressing three prerequisites: (i) adequate insertion with defined orientation and minimized iatrogenic harm, (ii) possibility of graft extraction for more precise positioning, and (iii) immediate fixation and stability. The method was specifically implemented for the implantation of disc-shaped osteochondral constructs, engineered by culture of human chondrocytes into a composite biomaterial, and validated by short-term insertion in cadaver ankle joints.

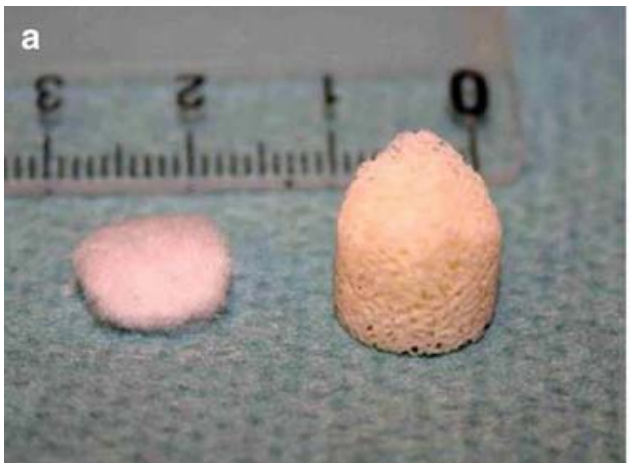

Fig. 1 a The Hyaff ${ }^{\circledR}-11$ non-woven mesh, on the left side of the picture, was shaped to fit exactly onto the Tutobone ${ }^{\circledR}$ cylinder. The upper contour of the Tutobone ${ }^{\circledR}$ cylinder, on the right side of the figure, was also preshaped to imitate the talar dome on the medial or

\section{Materials and methods}

Engineering of osteochondral grafts

The biphasic composite consisted of discs (10 mm diameter, $2 \mathrm{~mm}$ thickness) of esterified hyaluronic acid nonwoven meshes $\left(\right.$ Hyaff ${ }^{\circledR}-11$, Fidia Advanced Biopolymers, Abano Terme, IT) for the cultivation of the expanded chondrocytes (cartilage layer), which were combined with cylindrical plugs (10.6 mm diameter, $10-18 \mathrm{~mm}$ height) of decellularised bone (Tutobone ${ }^{\circledR}$-block, Tutogen Medical Gmbh, Neunkirchen a. Br., Germany) (bone layer), as described below. The Tutobone ${ }^{\circledR}$ cylinders were maintained with flat surfaces or pre-shaped using a high frequency ultrasound advise (Piezosurgery ${ }^{\circledR}$, mectron, Köln Dellbrück, Germany) to imitate the surface-contours of the medial or lateral talar dome (Fig. 1), usually presenting an angle between $70^{\circ}$ and $90^{\circ}$ in the frontal plane. The Hyaff ${ }^{\circledR}-11$ scaffolds were sutured to the Tutobone ${ }^{\circledR}$ blocks with six full thickness sutures (PDS 7-0, Ethicon, Johnson and Johnson, USA). The sutures were applied through six $0.2 \mathrm{~mm}$ channels, spaced at about $60^{\circ}$ from each other and drilled at an angle of about $45^{\circ}$ with respect to the upper surface of the Tutobone ${ }^{\circledR}$ cylinders, with the knots placed on the bone layer. The constructs were then gamma sterilised with 30 kiloGray (Studer Hard, Dänikon, Switzerland).

Adult human articular chondrocytes were collected postmortem from full-thickness biopsies of the femoral condyle of four individuals (range 25-45 years old), in accordance with the Local Ethics Committee and following informed consent of the relatives. Chondrocytes were isolated, expanded for about 8-10 doublings as previously described [4] and resuspended in Dulbecco's modified Eagle's medium containing $10 \%$ fetal bovine serum, $0.1 \mathrm{mM}$ non-essential amino acids, $1 \mathrm{mM}$ sodium

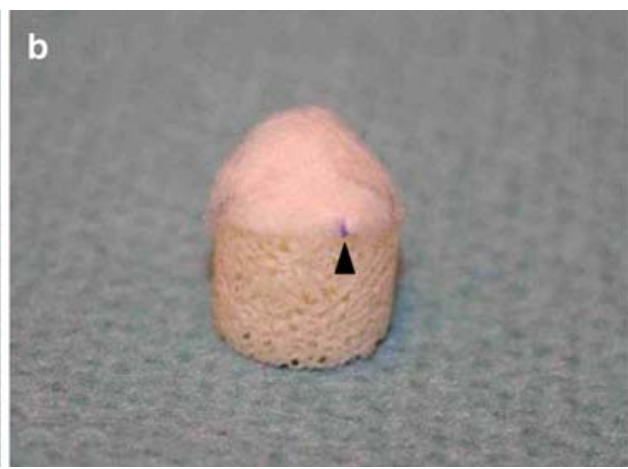

lateral side. b The Hyaff ${ }^{\circledR}-11$ and the Tutobone ${ }^{\circledR}$ cylinders were sutured together as explained in the methods section, prior to seeding with cells. The black arrowhead indicates the position of one surgical knot 


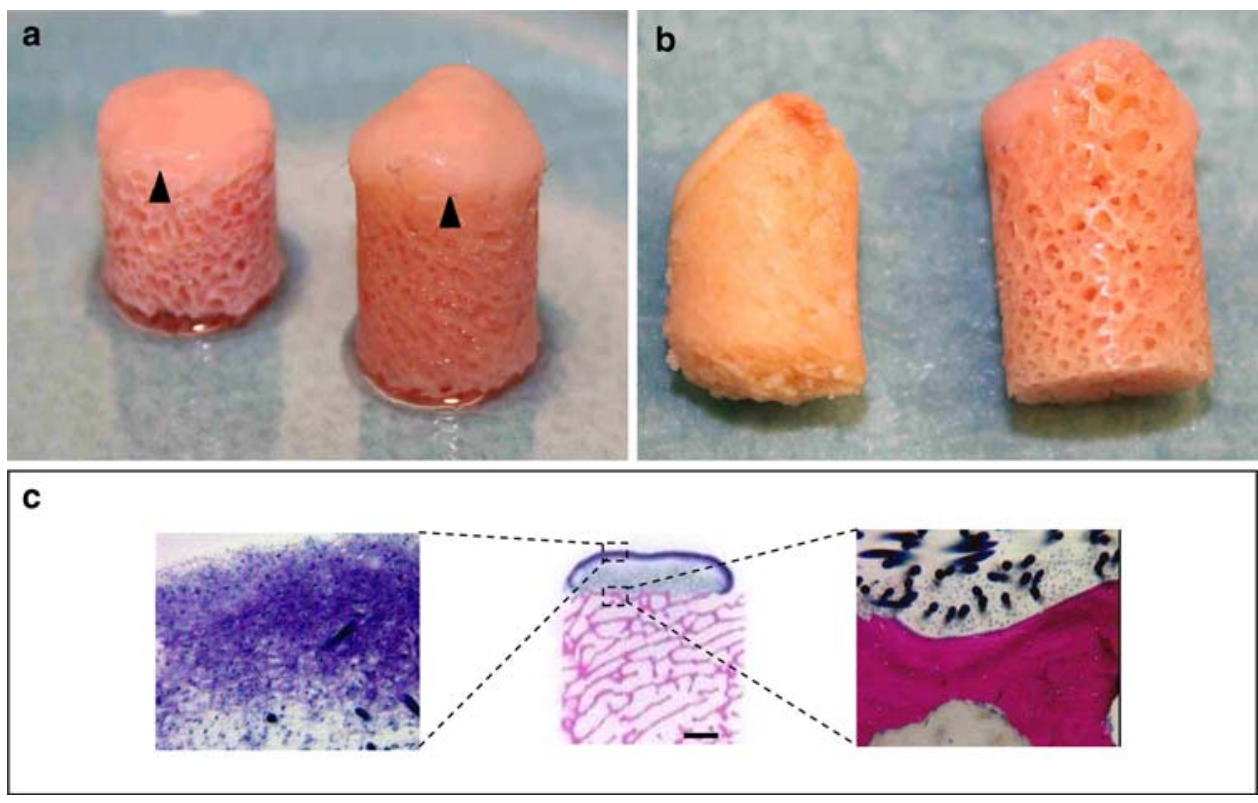

Fig. 2 a Engineered osteochondral grafts after 3 weeks of culture. The upper surface of the grafts was maintained flat (left specimen) or preshaped to mimic the contours of the talar medial or lateral dome (right specimen). The black arrowhead indicates the position of surgical knots, now partially covered by the deposited extracellular matrix. b The engineered osteochondral composite (right specimen)

pyruvate, $100 \mathrm{mM}$ HEPES buffer, $100 \mathrm{U} / \mathrm{ml}$ penicillin, $100 \mu \mathrm{g} / \mathrm{ml}$ streptomycin, and $0.29 \mathrm{mg} / \mathrm{ml} \mathrm{L-glutamine}$ (complete medium) at a density of $2.15 \times 10^{5}$ cells $/ \mathrm{ml}$. Aliquots of $70 \mu \mathrm{l}$ of cell suspension (corresponding to $15 \times 10^{6}$ cells) were statically loaded on the cartilage layers of the composite materials. Cell-seeded constructs were then cultured for 3 weeks in complete medium further supplemented with $0.1 \mathrm{mM}$ ascorbic acid, $10 \mu \mathrm{g} / \mathrm{ml}$ insulin and $10 \mathrm{ng} / \mathrm{ml}$ transforming growth factor- $\beta 3$ in a humidified $37 \% / 5 \% \mathrm{CO}_{2}$ incubator, with medium changes twice per week. The engineered osteochondral grafts, whose macroscopic appearance is displayed in Fig. 2a, were subsequently processed for histological analysis $(n=4)$ or used for the cadaver implantation study $(n=6)$, as described below.

\section{Histological analysis}

After 3 weeks' culture, osteochondral constructs were fixed in formalin/methanol, dehydrated in ascending alcohols, defatted in xylene and embedded in methylmethacrylate. Following polymerization, $200 \mu \mathrm{m}$ thick sections were obtained at intervals of $300 \mu \mathrm{m}$ using a saw microtome (Leica Sägemikrotom SP1600) with a diamond coated circular blade. The sections were then mounted on opaque plastic slides, ground and polished with a special grinding system (Exakt Schleifsystem 400 CS), and stained with was preshaped similarly to a native osteochondral cylinder extracted from a cadaver talus (left specimen). c Histological sections of one representative engineered osteochondral graft after 3 weeks' culture, following Giemsa/Eosin stain. The top layer consists of a thin layer of cartilaginous tissue, and some chondrocytes can be found at the interface between bone and cartilage layers. Scale bar $2 \mathrm{~mm}$

Giemsa/Eosin. The stained slides were evaluated with a Zeiss Axioplan microscope in transmitted light mode.

\section{Cadaver implantation}

Informed consent from the deceased donor's relatives was first obtained for the implantation of the engineered osteochondral constructs in the cadaveric tali. In total six osteochondral constructs were implanted in the defects created in the medial $(n=3)$ and later $(n=3)$ dome of the joints of two cadavers as described below. Considering the typical locations of OCL, a medial or lateral open approach to the talus with osteotomy of the medial or lateral malleolus was performed, as described by Gautier et al. [5]. OCL were created in a size (about $9 \mathrm{~mm}$ in diameter) which is in the range of the average diameter of typical talus lesions, using a commercially available drilling system (Arthrex Swiss AG, Volketswil, Switzerland). In accordance with the manufacturer's instructions, the blue extractor (inner diameter $9.6 \mathrm{~mm}$, outer diameter $10.3 \mathrm{~mm}$ ) was positioned directly over the defect on the medial and on the lateral edges of the talar dome, and hammered with caution into the defect at $45^{\circ}$ from the horizontal surface of the talus and $0^{\circ}$ in the sagittal plane (Fig. 3a). The milling cutter (inner diameter $9.5 \mathrm{~mm}$, outer diameter $10.5 \mathrm{~mm}$ ) was then drilled $20 \mathrm{~mm}$ deep into the bone and the osteochondral cylinders extracted (Fig. 3b). 

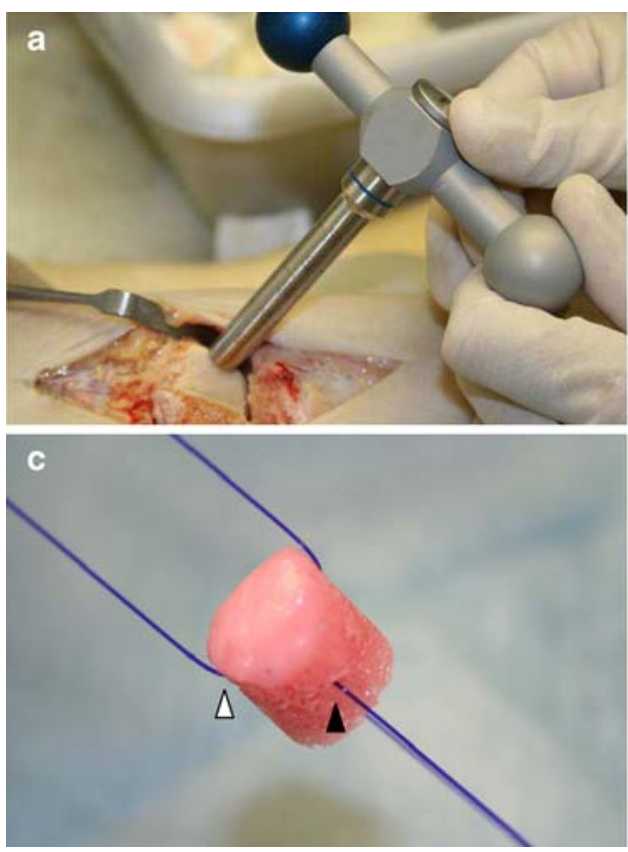

Fig. 3 a Osteochondral defects of the talus in the ankle joint were created by hand drilling the milling cutter (Arthrex Swiss AG, Volketswil, Switzerland, inner diameter $9.6 \mathrm{~mm}$, outer diameter $10.5 \mathrm{~mm}$ ) at $45^{\circ}$ to the horizontal surface of the talus and $0^{\circ}$ in the sagittal plane, for about $20 \mathrm{~mm}$ into the bone. b The picture shows the operation site, with the osteotomy of the medial malleolus and the osteochondral defect on the medial dome, following extraction of

The grafts were prepared by drilling two $0.6 \mathrm{~mm}$ channels perpendicular to each other through the Tutobone ${ }^{\circledR}$-cylinder of the engineered graft, at about 3-4 mm and 7-8 $\mathrm{mm}$, respectively, from the lower surface of the scaffold. Two resorbable surgical monofil sutures (PDS 20, Ethicon, Johnson and Johnson, USA) were then passed through the pre-drilled channels and used to precisely control the correct rotational and plane orientation of the implant in the defect. In particular, the upper suture was used for the anterograde implantation, to pull the graft into the defect, and the lower one for the retrograde correction, in case of a too deep insertion (Fig. 3c).

Before pulling the osteochondral graft into the defect, a special K-wire provided with an eyelet was drilled through the bottom of the osteochondral defect and through the talus, perforating the soft tissue of the contralateral side of the hindfoot (Fig. 3d). In the medial approach, the K-wire was directed toward the sinus tarsi, whereas in the lateral approach, it was introduced toward the medial talar neck.

\section{Dynamic graft stability test}

These tests were performed in order to qualitatively assess the immediate stability of the implanted grafts and to verify that they would not dislocate after the first ankle movements. After insertion of the grafts, the Achilles tendon was
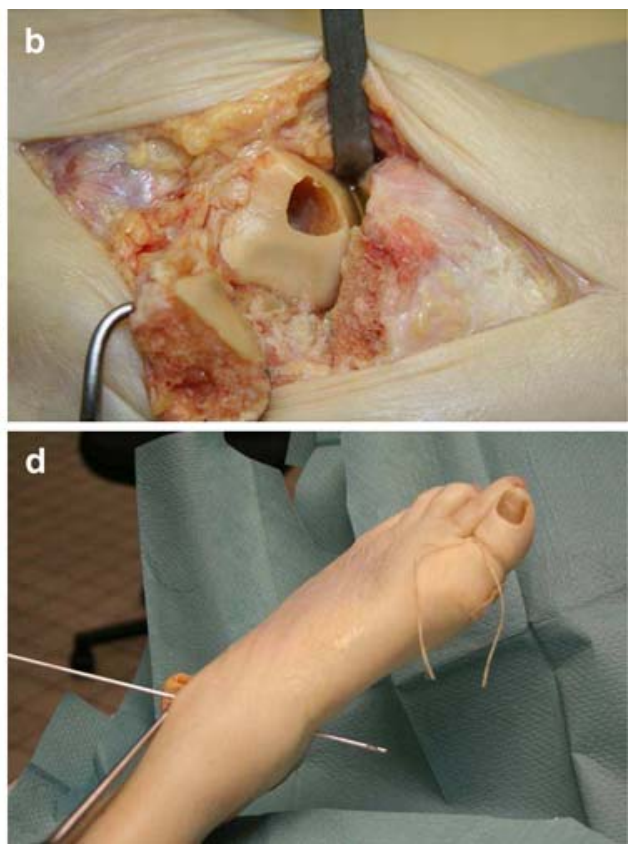

the cylinder. c The upper suture (black arrowhead) and lower suture (white arrowhead) were passed through the engineered osteochondral grafts, and the upper one was passed through the eyelet of the Kirschner wire (K-wire). d The special K-wire with an eyelet was drilled through the prepared osteochondral lesion, through the talus to the contralateral side of the hindfoot

cut, the osteotomies closed with screws and plates, and high-velocity maximal dorsi-/plantar flexion and in-/eversion movements of the ankle joint and hindfoot were performed for the duration of $1 \mathrm{~min}$. After release of the osteotomies, the implanted grafts were macroscopically inspected.

\section{Results}

Generation of the osteochondral grafts

After 3 weeks of culture, the cartilage layer $(1.5-2 \mathrm{~mm}$ thick) of the constructs displayed a glossy white appearance (Fig. 2a), and was macroscopically shaped similarly to native osteochondral cylinders (Fig. 2b). Histological staining indicated that the extracellular matrix was mainly confined in the upper part of the cartilage layer and that some of the seeded chondrocytes were present at the cartilage-bone layer interface, whereas the central region of the cartilage layer was predominantly acellular (Fig. 2c).

Implantation of the engineered osteochondral grafts

In each of the four cadaveric implantations, independently of the specific surgical approach (i.e., medial or lateral), the 
Fig. 4 Implantation of the engineered osteochondral graft into a cadaver osteochondral defect at the medial talar dome. a, b The graft is pulled with the upper suture into the defect and positioned correctly. $\mathbf{c}$ If the graft penetrates too deep into the bone, or is not oriented in the correct way, it can be pulled back with the lower suture. d Once the graft is precisely positioned, the surgical sutures are cut at surface level
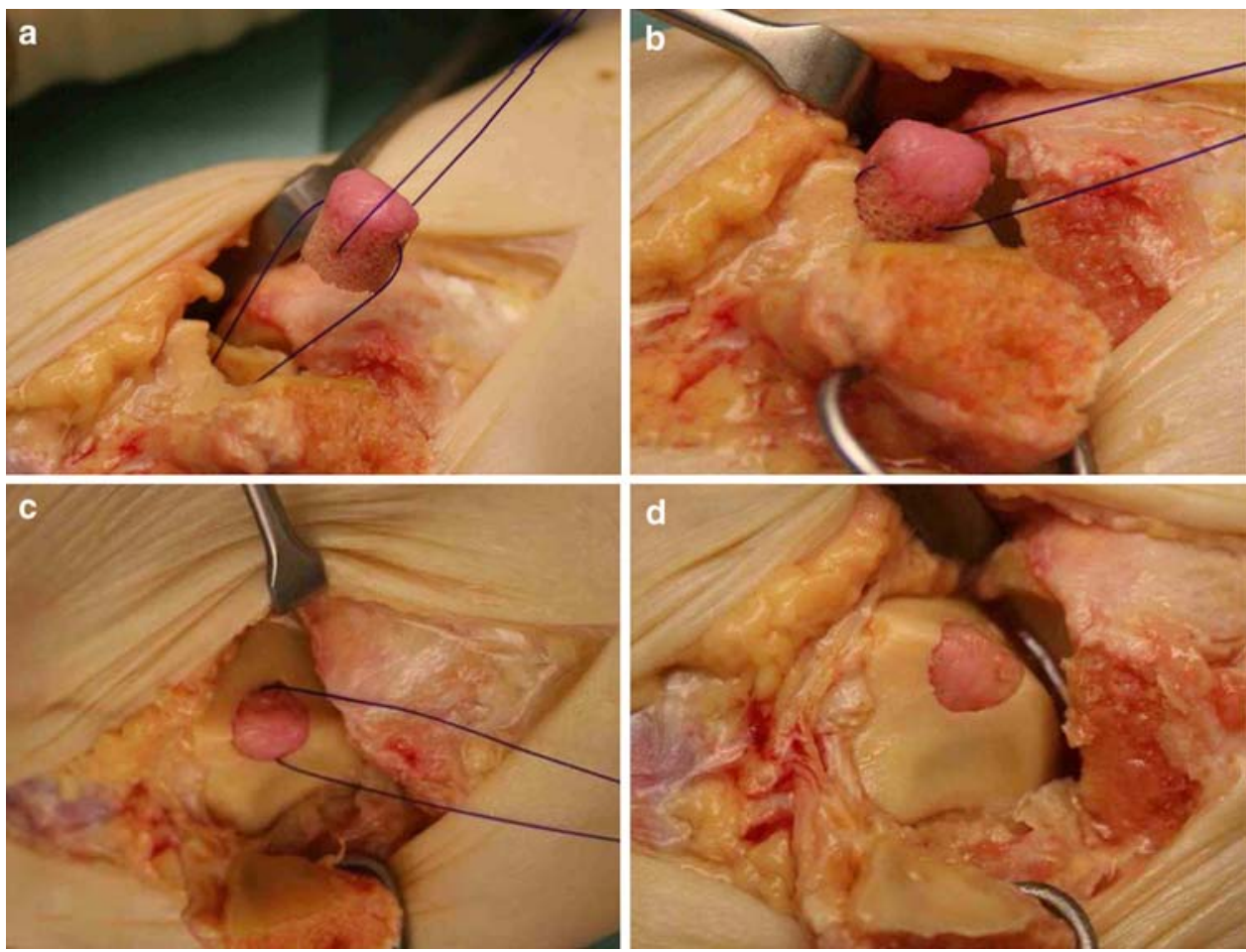

grafts could be inserted into the generated defects by pulling the upper suture out through the skin using the K-wire at the opposite side of the defects (Fig. 4a, b). By gentle pulling maneuvers, the cartilage layer of the grafts could be precisely positioned at the same level of the surrounding native cartilage shoulder, avoiding cartilage steps (Fig. 4c, d). The procedure did not involve any direct handling of the cartilage layer or of the composite interface, and thus no delamination of the layers or damage to the cell-seeded region was observed. In one case, the graft was first inserted too deep into the osteochondral defect, but the second suture allowed to pull it up and re-position it correctly.

Following the dynamic graft stability tests, the osteotomies were macroscopically anatomically stable and not dislocated. All grafts were without steps still in situ and no anatomical delamination of the cartilage layer from the bone layer was observed.

\section{Discussion}

In this study, we demonstrated that precise positioning of engineered osteochondral grafts may be obtained by using a suture system for pulling the implant from the bone layer, thereby minimizing iatrogenic damage associated with direct manipulation of the cartilage layer.

The developed procedure does not require additional fixation devices, which would bear the risk of displacement or intra-articular disturbance, but is critically dependent on the positioning of the $\mathrm{K}$-wire, to prevent damage of anatomical structures at the exit site. The pull-through technique is rather typical in ligament surgery (e.g., for anterior cruciate ligament reconstruction) and precaution techniques (e.g., careful blunt dissection of the soft tissue or fluoroscopic control of the K-wire direction) are well known procedures to avoid complications.

After an initially coarse insertion of the graft into the defect, the suture-based developed method allows to precisely adjust the tilt and height of the osteochondral graft in relation to the surrounding native cartilage shoulder, and thus to reach a perfect fitting. Even in case the osteochondral graft is undersized in depth and unwillingly pushed too deep into the OCL, the suture system can be used to readapt and adjust the superficial layers of native and engineered cartilage without damaging the implant, which would be hardly feasible using the conventional press-fit technique. This feature is crucial, as exact fitting and positioning of the osteochondral graft seems to be a key factor for clinical outcome after transplantation of autologous osteochondral grafts. In fact, incongruities in the articular surface are known to lead to significantly increased contact peak pressures of the surrounding cartilage, with consequent risk of osteoarthritic degeneration [11]. With the mosaicplasty technique, the surface incongruence with the surrounding cartilage remains an unsolved problem, since the autologous osteochondral plugs can only roughly be matched to the defect location 
[11]. In contrast, tissue engineered constructs can be produced with a defined shape and size and anatomically matched to a defect location, and thus require a more sophisticated positioning technique.

The immediate stability of the implant fixation in the cadaver model system was preliminarily validated by dynamic stability tests. Obviously, the short-duration test does not directly mimic continuous mechanical loading, and therefore does not allow to be predictive of the longterm graft survival. However, as known from other transplantation procedures using grafts even more vulnerable to mechanical loading (e.g., matrix associated chondrocyte implantation $\left(\mathrm{MACI}^{\circledR}\right)$, in general implant dislocation rarely occurs if its position is initially maintained [1].

In our study, the osteochondral grafts were engineered using a sturdy material for the bone layer, namely decellularised bone, and implanted in the ankle joint. Future studies will be required to assess whether the described technique could be adopted also in case more fragile/brittle materials are used or for transplantation of grafts in a different joint.

The engineered cartilage layer of the osteochondral grafts used in our experiments was not fully developed, and cells were confined at the peripheral regions, most likely due to the intrinsic mass transport limitations associated with static culture conditions [21]. A more homogeneous distribution of cells and of hyaline-like extracellular matrix throughout the cartilage layer and at the interface with the bone layer, could be achieved by culture under defined regimes of fluid flow, within dedicated bioreactor systems [14]. An improvement in the maturation of the tissue, with associated increase in the mechanical properties, could play an important role to support earlier post-operative rehabilitation.

In conclusion, we developed and short-term validated within cadaveric ankle joints a novel implantation technique for engineered osteochondral cylinders. The method bypasses the typical pushing or hammering which is necessary for press-fit insertion of autologous osteochondral plugs in mosaicplasty surgery, and which could not be tolerated by an engineered construct, due to the expected lower mechanical compliance [13]. Moreover, the procedure allows precise positioning and orientation of the grafts, which is essential for constructs that would be designed to be precisely congruent with the surrounding cartilage surface. If further pre-clinical investigations confirm the promising results of our cadaver study, this technique will facilitate and improve engineered osteochondral graft transplantation and may be even considered for grafting of autologous osteochondral cylinders.

Acknowledgments The study was partially financed by the Swiss National Science Foundation (Grant No. 3200B0-110054) and by the Deutsche Arthrose-Hilfe e.V. We would like to thank Tutogen
Medical Gmbh, Neunkirchen, Germany for providing the Tutobone ${ }^{\circledR}$ cylinders and Fidia Advanced Biopolymers (FIDIA, Abano Therme, Italy) for providing the Hyaff ${ }^{\circledR}-11$ non-woven meshes.

\section{References}

1. Bachmann G, Basad E, Lommel D, Steinmeyer J (2004) MRI in the follow-up of matrix-supported autologous chondrocyte transplantation (MACI) and microfracture. Radiologe 44:773-782

2. Bauer M, Jonsson K, Linden B (1987) Osteochondritis dissecans of the ankle. A 20-year follow-up study. J Bone Joint Surg Br 69:93-96

3. Canale ST, Belding RH (1980) Osteochondral lesions of the talus. J Bone Joint Surg Am 62:97-102

4. Candrian C, Vonwil D, Barbero A, Bonacina E, Miot S, Farhadi J, Wirz D, Dickinson S, Hollander A, Jakob M, Li Z, Alini M, Heberer M, Martin I (2008) Engineered cartilage generated by nasal chondrocytes is responsive to physical forces resembling joint loading. Arthritis Rheum 58:197-208

5. Gautier E, Kolker D, Jakob RP (2002) Treatment of cartilage defects of the talus by autologous osteochondral grafts. J Bone Joint Surg Br 84:237-244

6. Giannini S, Vannini F, Buda R (2002) Osteoarticular grafts in the treatment of OCD of the talus: mosaicplasty versus autologous chondrocyte transplantation. Foot Ankle Clin 7:621-633

7. Hangody L, Fules P (2003) Autologous osteochondral mosaicplasty for the treatment of full-thickness defects of weightbearing joints: ten years of experimental and clinical experience. J Bone Joint Surg Am 85-A suppl 2:25-32

8. Hangody L, Kish G, Modis L, Szerb I, Gaspar L, Dioszegi Z, Kendik Z (2001) Mosaicplasty for the treatment of osteochondritis dissecans of the talus: two to seven year results in 36 patients. Foot Ankle Int 22:552-558

9. Huntley JS, Bush PG, McBirnie JM, Simpson AH, Hall AC (2005) Chondrocyte death associated with human femoral osteochondral harvest as performed for mosaicplasty. J Bone Joint Surg Am 87:351-360

10. Kandel RA, Grynpas M, Pilliar R, Lee J, Wang J, Waldman S, Zalzal P, Hurtig M (2006) Repair of osteochondral defects with biphasic cartilage-calcium polyphosphate constructs in a sheep model. Biomaterials 27:4120-4131

11. Koh JL, Wirsing K, Lautenschlager E, Zhang LO (2004) The effect of graft height mismatch on contact pressure following osteochondral grafting: a biomechanical study. Am J Sports Med 32:317-320

12. Martin I, Miot S, Barbero A, Jakob M, Wendt D (2007) Osteochondral tissue engineering. J Biomech 40:750-765

13. Martin I, Obradovic B, Treppo S, Grodzinsky AJ, Langer R, Freed LE, Vunjak-Novakovic G (2000) Modulation of the mechanical properties of tissue engineered cartilage. Biorheology 37:141-147

14. Martin I, Wendt D, Heberer M (2004) The role of bioreactors in tissue engineering. Trends Biotechnol 22:80-86

15. Nabavi-Tabrizi A, Turnbull A, Dao Q, Appleyard R (2002) Chondrocyte damage following osteochondral grafting using metal and plastic punches: comparative study in an animal model. J Orthop Surg (Hong Kong) 10:170-172

16. O'Driscoll SW (1998) The healing and regeneration of articular cartilage. J Bone Joint Surg Am 80:1795-1812

17. Schaefer D, Martin I, Shastri P, Padera RF, Langer R, Freed LE, Vunjak-Novakovic G (2000) In vitro generation of osteochondral composites. Biomaterials 21:2599-2606

18. Schenck RC Jr, Goodnight JM (1996) Osteochondritis dissecans. J Bone Joint Surg Am 78:439-456 
19. Tol JL, Struijs PA, Bossuyt PM, Verhagen RA, van Dijk CN (2000) Treatment strategies in osteochondral defects of the talar dome: a systematic review. Foot Ankle Int 21:119-126

20. Valderrabano V, Hintermann B, Horisberger M, Fung TS (2006) Ligamentous posttraumatic ankle osteoarthritis. Am J Sports Med 34:612-620

21. Wendt D, Stroebel S, Jakob M, John GT, Martin I (2006) Uniform tissues engineered by seeding and culturing cells in $3 \mathrm{D}$ scaffolds under perfusion at defined oxygen tensions. Biorheology 43:481-488

22. Whittaker JP, Smith G, Makwana N, Roberts S, Harrison PE, Laing P, Richardson JB (2005) Early results of autologous chondrocyte implantation in the talus. J Bone Joint Surg $\mathrm{Br}$ 87:179-183 